\title{
PROPAGAÇÃO DE Cestrum corymbosum POR SEMENTES E ESTAQUIA
}

\author{
Christopher Thomas Blum ${ }^{1}$, Valdeci Constantino ${ }^{2}$, Karen Koch Fernandes de Souza ${ }^{3}$, \\ Antonio Carlos Nogueira ${ }^{1}$
}

${ }^{1}$ Eng. Florestal, Dr., Depto. de Ciências Florestais, UFPR, Curitiba, PR, Brasil - ctblum@ufpr.br; nogueira@ufpr.br

${ }^{2}$ Eng. Florestal M.Sc., Depto. de Estatística, UFPR, Curitiba, PR, Brasil - deco@ufpr.br

${ }^{3}$ Eng $^{\mathrm{a}}$ Florestal, M.Sc., PUC do Paraná, Curitiba, PR, Brasil - karen.souza @ pucpr.br

Recebido para publicação: 17/11/2011 - Aceito para publicação: 05/02/2013

\begin{abstract}
Resumo
Cestrum corymbosum é um arbusto ornamental nativo do Brasil. A pesquisa visou estudar sua propagação sexuada e vegetativa, avaliando a germinação e o crescimento e testando o efeito do tamanho das estacas e do ácido indolbutírico (AIB) no seu enraizamento e desenvolvimento. Para avaliar a germinação, foram utilizadas seis repetições de 100 sementes. Em seguida, 200 plântulas foram transferidas para embalagens individuais mantidas em canteiro. $\mathrm{O}$ experimento de propagação vegetativa, com delineamento inteiramente casualizado em arranjo fatorial $3 \times 2$, constituiu-se na combinação de três concentrações de $\operatorname{AIB}\left(0,1000\right.$ e 2000 mg.L $\left.\mathrm{L}^{-1}\right)$ e dois tamanhos de estacas (8 e $15 \mathrm{~cm})$. As estacas foram plantadas em substrato comercial Plantmax $\mathrm{HA}^{\circledR}$. No experimento de propagação sexuada, verificou-se elevada germinação (92\%), assim como alta taxa de sobrevivência após repicagem para recipientes individuais $(99,5 \%)$. Para o experimento de propagação vegetativa, foi detectada influência significativa do tamanho das estacas em relação à sobrevivência, enraizamento $(P<0,01)$ e número de folhas $(P<0,05)$. Estacas de $8 \mathrm{~cm}$ apresentaram melhor sobrevivência $(93,3 \%)$ e enraizamento $(91,3 \%)$. A aplicação de concentrações de AIB não resultou em diferenças significativas $(P<0,01)$, demonstrando não ser necessária para o enraizamento dessa espécie.

Palavras-chave: Germinação; enraizamento; ácido indolbutírico; espécie nativa; Solanaceae.
\end{abstract}

\begin{abstract}
Propagation of Cestrum corymbosum by seeds and cuttings. Cestrum corymbosum is an ornamental bush native from Brazil. This research aimed to study the sexual and vegetative propagation of this species, evaluating germination and growth of the seedlings, and testing the influence of indolebutyric acid (IBA) and cuttings size on its rooting and development. In order to evaluate germination, six repetitions of 100 seeds were considered. After that, 200 seedlings have been transplanted to individual packages kept in a bed. The vegetative propagation experiment has been arranged in a $3 \mathrm{x}$ 2 factorial completely randomized design that comprised the combination of three IBA concentrations $\left(0,1000\right.$ and $\left.2000 \mathrm{mg} \cdot \mathrm{L}^{-1}\right)$ for two cuttings sizes $(8$ and $15 \mathrm{~cm})$. The cuttings were planted in commercial substrate Plantmax $\mathrm{HA}^{\circledR}$. A high germination $(92 \%)$ has been verified. The survival after transplantation was very high (99.5\%). It was detected statistically significant influence of the cuttings size on plants survival, rooting $(P<0.01)$ and leaves number $(P<0.05)$. The cuttings of $8 \mathrm{~cm}$ presented better survival $(93.3 \%)$ and rooting $(91.3 \%)$ rates. The treatment with IBA in distinct concentrations did not produce results with significant differences $(P<0.01)$.

Keywords: Germination; rooting; indolebutyric acid; native species; Solanaceae.
\end{abstract}

\section{INTRODUÇÃO}

A espécie Cestrum corymbosum Schldl. (Solanaceae), conhecida como coerana-amarela, é um arbusto perene e ereto, com porte de um a dois metros e intensa ramificação. Possui folhas coriáceas e luzidias, podendo ser lanceoladas, elípticas ou elíptico-ovaladas. Suas inflorescências são do tipo corimbo, terminais ou agrupadas em ramos laterais curtos. As flores possuem corola tubulosa e cor amarelo-ouro. A floração é abundante e ocorre entre a primavera e o outono. Os frutos são bagas ovoides de cor escura (LORENZI, 2008; LORENZI; SOUZA, 2008). As sementes do gênero Cestrum são 
angulosas, apenas um pouco mais longas do que largas, marrons, com embrião reto ou levemente curvo, radícula cilíndrica e ínfera (SOARES et al., 2007).

C. corymbosum é nativa do Brasil, particularmente comum no sul do país, com limite de ocorrência no nordeste da Argentina. É típica de capoeiras e bordas de florestas, apreciando também ambientes úmidos (LORENZI, 2008). Caracteriza-se como planta pioneira de dispersão zoocórica, principalmente por aves. No que se refere ao paisagismo, é muito adequada para cultivo em jardins, como planta isolada ou formando maciços nas áreas mais amplas (LORENZI; SOUZA, 2008). Apesar dessas características e potencialidades de uso no paisagismo, ainda assim é apenas eventualmente cultivada (LORENZI, 2008).

A reduzida utilização dessa espécie decorre da falta de informações existentes, especialmente no que se refere a sua propagação e manejo. Lorenzi e Souza (2008) citam brevemente que a multiplicação de $C$. corymbosum pode ser realizada por sementes ou estacas. No entanto, além dessas informações, não existem estudos específicos sobre sua propagação. Por outro lado, estudos de propagação foram realizados com outras duas espécies do gênero, Cestrum nocturnum L. (dama-da-noite) e Cestrum roseum Kunth (jessamina-rosa) (AL-SAWAF et al., 1994; LOPES et al., 2000; FERNANDEZ et al., 2007). Ambas as espécies apresentam características morfológicas e ornamentais relativamente semelhantes às de C. corymbosum.

Para C. nocturnum, Al-Sawaf et al. (1994) testaram o efeito de diferentes épocas de plantio e distintas concentrações de ácido indolbutírico (AIB) sobre o enraizamento de estacas lenhosas. Os referidos autores destacaram que as estacas tratadas com $500 \mathrm{mg} \cdot \mathrm{L}^{-1}$ de AIB apresentaram o melhor desenvolvimento. Estudando a mesma espécie, Fernandez et al. (2007) compararam o enraizamento de estacas lenhosas e herbáceas, com e sem aplicação de AIB, sendo que a conclusão foi que estacas lenhosas mostraram-se mais propícias, especialmente quando tratadas com o regulador vegetal.

No Brasil existem alguns estudos com Brunfelsia uniflora (Pohl.) D. Don. (manacá-de-cheiro), outro arbusto ornamental pertencente à família Solanaceae. Rocha et al. (2004) testaram a influência de diferentes concentrações de AIB e suas formas de aplicação (em solução ou em talco) no enraizamento de estacas, concluindo que as estacas tratadas com a auxina em solução apresentaram maior sobrevivência. Althaus-Ottmann et al. (2006) também estudaram a propagação vegetativa de B. uniflora através da aplicação de AIB, tendo como conclusão que a aplicação de ácido indolbutírico é desnecessária para essa espécie, uma vez que não aumentou a indução de raízes e calos.

Com relação à propagação por sementes, é notável a inexistência de estudos para espécies do gênero Cestrum e até mesmo para outras solanáceas ornamentais. Os estudos de propagação sexuada da família Solanaceae restringem-se às espécies de valor alimentício, sobretudo do gênero Solanum (MIRANDA et al., 1992; SOUZA et al., 1997; LOPES et al., 2005; LAVIOLA et al., 2006; GARCIA et al., 2008; PEREIRA et al., 2011).

Desse modo, considerando o grande potencial ornamental e a carência de informações relativas à propagação de Cestrum corymbosum, o presente estudo teve como objetivos: 1) avaliar a germinação e o desenvolvimento inicial de plântulas; 2) avaliar a propagação vegetativa testando a influência de diferentes concentrações de AIB e do tamanho das estacas sobre seu enraizamento e desenvolvimento.

\section{MATERIAL E MÉTODOS}

\section{Propagação por sementes}

Frutos de Cestrum corymbosum foram coletados de plantas matrizes localizadas na área rural do município de Campina Grande do Sul, PR, no mês de dezembro de 2008. O beneficiamento das sementes e as análises de massa fresca e germinação foram conduzidos no Laboratório de Análise de Sementes Florestais no Campus III da Universidade Federal do Paraná, em Curitiba, PR.

As sementes foram despolpadas em peneira fina sob água corrente. Para obter a estimativa da massa de mil sementes, foram utilizadas cinco repetições de 100 sementes.

Para o experimento de germinação, as sementes foram dispostas em caixas plásticas "gerbox" sobre papel toalha mantido permanentemente umedecido, mas sem que as sementes ficassem submersas. $\mathrm{O}$ experimento foi realizado em germinador a $25{ }^{\circ} \mathrm{C}$ e sob iluminação contínua, tendo sido instalado quatro dias após a coleta dos frutos. 
Utilizou-se delineamento experimental inteiramente casualizado, com seis repetições, sendo cada parcela representada por 100 sementes. Foram feitas contagens diárias das sementes germinadas, sendo, para tal, utilizado como critério a protrusão da radícula. As contagens prolongaram-se até o fim da germinação. Para avaliar a velocidade de germinação, foi considerado o índice de velocidade de germinação (IVG) (MAGUIRE, 1962).

As plântulas retiradas do germinador foram plantadas em bandejas plásticas com substrato comercial Plantmax HA ${ }^{\circledR}$, composto por casca de pínus, turfa, vermiculita expandida e carvão moído, em proporções não divulgadas, sendo mantidas no Laboratório de Análise de Sementes Florestais até atingirem tamanho adequado para a repicagem. Passados 30 dias após o início do experimento, 200 plântulas foram repicadas no Viveiro Chauá, no município de Campo Largo, PR. A repicagem foi realizada em embalagens plásticas individuais $(10 \times 20 \mathrm{~cm})$ preenchidas com substrato argiloso peneirado, sendo o experimento mantido em canteiro externo com sombreamento de $50 \%$ e irrigação diária. Três meses após a semeadura, foram avaliados a sobrevivência, a altura e o número de folhas das mudas.

\section{Propagação por estacas}

As estacas caulinares de Cestrum corymbosum foram coletadas de ramos semilenhosos de plantas matrizes adultas existentes nos arredores do Viveiro Chauá, município de Campo Largo, PR, no mês de dezembro de 2008. Foram confeccionadas estacas caulinares semilenhosas de dois comprimentos: $8 \mathrm{~cm}$ e $15 \mathrm{~cm}$. Foi mantida uma padronização de diâmetro das estacas, que variou entre 0,4 e 0,6 cm.

Cada estaca foi preparada com corte em bisel na base e corte reto acima da última gema axilar, mantendo-se duas folhas na porção apical, reduzidas à metade. Em seguida, as estacas foram mergulhadas em hipoclorito de sódio a $0,5 \%$ durante 10 minutos, para assepsia. Após a preparação, a base de cada estaca foi imersa por 10 segundos em diferentes soluções de ácido indolbutírico $\left(0,1000\right.$ e $\left.2000 \mathrm{mg} . \mathrm{L}^{-1}\right)$. O plantio foi realizado no mesmo dia em que as estacas foram coletadas, em caixas de madeira de $50 \times 50 \times 10 \mathrm{~cm}$ contendo substrato comercial Plantmax $\mathrm{HA}^{\circledR}$, composto por casca de pínus, turfa, vermiculita expandida e carvão moído, em proporções não divulgadas. Após o plantio, as estacas foram mantidas em ambiente externo, com sombreamento de $80 \%$ e irrigação diária.

A avaliação do experimento foi realizada 90 dias após sua instalação. Foram avaliadas a porcentagem de sobrevivência (estacas vivas, enraizadas ou não), porcentagem de estacas enraizadas e o número médio de folhas novas por estaca. Mensalmente (aos 30, 60 e 90 dias), foram realizadas avaliações para detectar o enraizamento das estacas. Durante essas avaliações, cada estaca foi parcialmente desenterrada e imediatamente replantada, de modo a não causar danos às raízes.

$\mathrm{O}$ delineamento estatístico utilizado foi o inteiramente casualizado, em arranjo fatorial $3 \times 2$ (concentrações de AIB x tamanho das estacas), com 5 repetições de 10 estacas por parcela, totalizando 300 estacas. A homogeneidade das variâncias dos tratamentos foi analisada pelo teste de Bartlett $(P<0,05)$. As variáveis cujas variâncias se mostraram homogêneas foram submetidas à análise da variância $(P<0,01$ e/ou $P<0,05)$, e as que apresentaram diferenças significativas tiveram suas médias comparadas pelo teste de Tukey ao nível de $5 \%$.

\section{RESULTADOS E DISCUSSÃO}

\section{Propagação por sementes}

A massa estimada de mil sementes de Cestrum corymbosum foi de 6,46 $\pm 0,09 \mathrm{~g}$, com coeficiente de variação de $11,2 \%$, pouco acima do coeficiente recomendado pelas Regras para Análises de Sementes (BRASIL, 1992).

O processo de germinação foi considerado uniforme, iniciando a partir do $5^{\circ}$ dia após a semeadura e estendendo-se até o $9^{\circ}$ dia (Tabela 1). Após esse período, as poucas sementes remanescentes apresentaram-se deterioradas e infestadas por patógenos. Embora isso deva ser confirmado por estudos mais aprofundados, a rapidez e intensidade de germinação de Cestrum corymbosum verificados no presente experimento são um indicativo de que essa espécie não apresenta dormência, ao contrário do que se observa em outras solanáceas, como Solanum tuberosum (batata) e S. lycocarpum (lobeira), as quais apresentaram maiores índices de germinação somente quando submetidas a tratamentos de superação de dormência (SOUZA et al., 1997; GONZAGA et al., 2007). 
Tabela 1. Porcentagem de germinação e índice de velocidade de germinação (IVG) de sementes de Cestrum corymbosum, nove dias após a semeadura.

Table 1. Percentage of germination and germination speed index (IVG) of Cestrum corymbosum seeds, nine days after the sowing.

\begin{tabular}{lcc}
\hline Parâmetros & Germinação (\%) & IVG \\
\hline Média & $91,67 \pm 4,41$ & $15,13 \pm 0,70$ \\
Coeficiente de variação (\%) & 4,81 & 4,63 \\
\hline
\end{tabular}

Nota: a $95 \%$ de probabilidade.

A porcentagem de germinação foi elevada, considerando não ter sido aplicado nenhum tratamento para estimular o processo. Esse comportamento não é um padrão para a família Solanaceae, tendo em vista que outras espécies, como Solanum gilo (jiloeiro), S. lycocarpum, S. melongena L. (berinjela), S. paniculatum (jurubeba), S. sessiliflorum (cubiú) e $S$. tuberosum apresentam maiores restrições para a germinação. As espécies citadas demonstraram resultados de germinação distintos, dependendo dos tratamentos aos quais foram submetidas (variação de substrato, temperatura, posição do fruto na planta, época de colheita e substâncias inibidoras de dormência) (MIRANDA et al., 1992; SOUZA et al., 1997; LOPES et al., 2005; LAVIOLA et al., 2006; GONZAGA et al., 2007; GARCIA et al., 2008).

A velocidade de germinação (Tabela 1) apresentada pelas sementes de C. corymbosum foi razoavelmente elevada quando comparada aos resultados obtidos em experimentos com outras espécies de Solanaceae. Laviola et al. (2006) obtiveram um IVG médio de apenas 2,70 para Solanum gilo. Para S. sessiliflorum, Lopes et al. (2005) e Pereira et al. (2011) registraram IVGs máximos variando entre 6,0 e 7,0 .

A grande capacidade de estabelecimento das plântulas foi comprovada pelos valores obtidos 90 dias após a semeadura (Tabela 2), com destaque para a elevada sobrevivência, o que reafirma seu potencial de utilização na horticultura ornamental. Em comparação a outras espécies, pode-se considerar seu crescimento inicial em altura $(14,6 \mathrm{~cm})$ como intermediário. Estudando Schinus terebinthifolius (aroeira-vermelha), Caldeira et al. (2008) verificaram altura máxima maior $(31,2 \mathrm{~cm})$ no mesmo período de 90 dias. É importante salientar que, no estudo de Caldeira et al. (2008), foram utilizados substratos distintos, que possivelmente potencializaram o desenvolvimento das plântulas.

Tabela 2. Valores médios de altura, número de folhas novas e sobrevivência das plântulas de Cestrum corymbosum, 90 dias após sua semeadura.

Table 2. Means values of height, number of leaves and survival of seedlings of Cestrum corymbosum, 90 days after the sowing.

\begin{tabular}{lccc}
\hline Parâmetros & Altura $(\mathbf{c m})$ & $\mathbf{N}^{\mathbf{0}}$ folhas novas & Sobrevivência (\%) \\
\hline Média & $14,57 \pm 0,80 *$ & $13,18 \pm 0,76^{*}$ & $99,50 \pm 1,58^{*}$ \\
Coeficiente de variação (\%) & 5,52 & 5,78 & 1,59 \\
\hline
\end{tabular}

Nota: a $95 \%$ de probabilidade.

\section{Propagação por estacas}

Aos 30 dias de experimento, verificou-se que o processo de enraizamento foi iniciado, sendo detectadas estacas enraizadas em todos os tratamentos. Aos 60 dias após o plantio, a maior parte das estacas se encontrava enraizada. Por fim, aos 90 dias, ocorreu um aumento de apenas $6,0 \%$ de estacas de $8 \mathrm{~cm}$ enraizadas com $1000 \mathrm{mg} . \mathrm{L}^{-1}$ de AIB, e de $4,0 \%$ de estacas de $8 \mathrm{~cm}$ enraizadas com $0 \mathrm{mg} . \mathrm{L}^{-1}$ de AIB (controle). Nos demais tratamentos, o aumento de estacas enraizadas entre 60 e 90 dias não superou os $2,0 \%$.

Esse período de enraizamento pode ser considerado relativamente reduzido quando comparado ao necessário para outras espécies. Em experimento com Brunfelsia uniflora, outra solanácea arbustiva ornamental, foi verificado ser necessário um período maior para indução de raízes, considerando que após 120 dias ainda não se havia alcançado mais de 50\% de enraizamento para nenhum dos tratamentos (ALTHAUS-OTTMANN et al., 2006).

Para as três variáveis analisadas (porcentagem de sobrevivência, porcentagem de estacas enraizadas e número de folhas novas por estaca), não houve interação significativa $(P<0,01)$ entre a 
concentração de AIB e o tamanho das estacas, indicando a independência dos fatores testados. Também não houve diferença significativa entre as diferentes concentrações de AIB $(P<0,01)$. Foi encontrada diferença significativa apenas entre os tamanhos de estacas, para todas as variáveis: porcentagem de sobrevivência, porcentagem de estacas enraizadas $(P<0,01)$ e número de folhas novas por estaca $(P<0,05)$.

No que se refere à sobrevivência, foram verificadas porcentagens significativamente maiores para as estacas de $8 \mathrm{~cm}$ (Tabela 3), as quais também se sobressaíram sobre as estacas de $15 \mathrm{~cm}$, por terem apresentado maior taxa de enraizamento (Tabela 4).

Tabela 3. Porcentagem de sobrevivência das estacas de Cestrum corymbosum, considerando dois tamanhos de estacas submetidas a três diferentes concentrações de ácido indolbutírico (AIB), após 90 dias.

Table 3. Percentage of survival of Cestrum corymbosum cuttings, regarding two sizes of cuttings submitted to three different concentrations of indolebutyric acid (IBA), after 90 days.

\begin{tabular}{|c|c|c|c|c|}
\hline \multirow{2}{*}{$\begin{array}{l}\text { Tamanho das estacas } \\
(\mathrm{cm})\end{array}$} & \multicolumn{3}{|c|}{ AIB } & \multirow{2}{*}{ Médias } \\
\hline & 0 mg.L ${ }^{-1}$ & 1000 mg. L $^{-1}$ & 2000 mg. L $^{-1}$ & \\
\hline 8 & 96,0 & 90,0 & 94,0 & $93,3 \mathrm{~A}$ \\
\hline 15 & 64,0 & 72,0 & 80,0 & $72,0 \mathrm{~B}$ \\
\hline Médias & $80,0 \mathrm{a}$ & $81,0 \mathrm{a}$ & $87,0 \mathrm{a}$ & \\
\hline
\end{tabular}

Tabela 4. Porcentagem de estacas enraizadas de Cestrum corymbosum, considerando dois tamanhos de estacas submetidas a três diferentes concentrações de ácido indolbutírico (AIB), após 90 dias.

Table 4. Percentage of rooted Cestrum corymbosum cuttings, regarding two sizes of cuttings submitted to three different concentrations of indolebutyric acid (IBA), after 90 days.

\begin{tabular}{lcccc}
\hline \multirow{2}{*}{$\begin{array}{l}\text { Tamanho das estacas } \\
(\mathbf{c m})\end{array}$} & \multicolumn{3}{c}{ AIB } & \multirow{2}{*}{ Médias } \\
\cline { 2 - 4 } & $\mathbf{0 ~ m g . \mathbf { L } ^ { - 1 }}$ & $\mathbf{1 0 0 0} \mathbf{~ m g . L}^{-\mathbf{1}}$ & $\mathbf{2 0 0 0} \mathbf{~ m g . L}^{-\mathbf{1}}$ & \\
\hline 8 & 90,0 & 90,0 & 94,0 & $91,3 \mathrm{~A}$ \\
15 & 64,0 & 72,0 & 76,0 & $70,7 \mathrm{~B}$ \\
\hline Médias & $77,0 \mathrm{a}$ & $81,0 \mathrm{a}$ & $85,0 \mathrm{a}$ & \\
\hline
\end{tabular}

Nota: médias seguidas da mesma letra maiúscula na vertical e minúscula na horizontal não diferem significativamente entre si pelo teste de Tukey ao nível de $5 \%$. Coeficiente de variação igual a $14,78 \%$.

A influência do tamanho das estacas sobre seus percentuais de enraizamento e sobrevivência varia consideravelmente entre espécies. O melhor desempenho de estacas pequenas $(10 \mathrm{~cm})$ também foi registrado para Melaleuca alternifolia (melaleuca) e Malpighia emarginata (acerola), duas lenhosas que apresentaram tendências lineares negativas de enraizamento e sobrevivência com relação ao aumento do comprimento das estacas (LIMA et al., 2006; OLIVEIRA et al., 2008). Por outro lado, efeito contrário foi constatado por Biasi e Costa (2003) para Lippia alba (erva-cidreira), que apresentou melhores índices de enraizamento no tratamento de estacas compridas $(20 \mathrm{~cm})$. Existem também espécies cujo potencial de enraizamento parece não depender do comprimento das estacas, como constatado para Fuchsia regia (brinco-de-princesa), que apresentou índices de enraizamento elevados e semelhantes para estacas de 7, 14 e $21 \mathrm{~cm}$ (ALCÂNTARA et al., 2008).

$\mathrm{O}$ maior sucesso de enraizamento e desenvolvimento em estacas longas é atribuído à maior quantidade de reservas presentes, as quais podem ser utilizadas para a formação de raízes novas e brotos (HARTMANN et al., 2011). Por outro lado, Lima et al. (2006) destacaram que estacas grandes podem ser mais suscetíveis à desidratação, devido à sua grande superfície exposta e à maior demanda de água para suprir seu tecido vivo. Desse modo, considerando o pior desempenho das estacas mais longas no presente estudo, uma possibilidade a ser considerada é a de que estacas de C. corymbosum possuem razoável sensibilidade à desidratação, ainda que esse aspecto não tenha sido quantificado no experimento. Serão necessários estudos mais aprofundados para confirmar os efeitos da desidratação e de outros fatores, como a translocação de reguladores endógenos, no enraizamento de estacas de diferentes tamanhos de $C$. corymbosum. 
A despeito de não ter sido detectada diferença significativa entre as concentrações de AIB, a aplicação do regulador vegetal parece ter exercido sensível efeito positivo na sobrevivência e consequente enraizamento das estacas de $15 \mathrm{~cm}$. De fato, as estacas de $15 \mathrm{~cm}$ submetidas à concentração de $2.000 \mathrm{mg} . \mathrm{L}^{-1}$ de AIB apresentaram índices de sobrevivência e enraizamento $16 \%$ e $12 \%$ mais elevados que o controle. É possível que o regulador vegetal tenha acelerado o processo de enraizamento dessas estacas, tornando-as mais aptas a enfrentar os efeitos adversos da desidratação, conforme Zuffellato-Ribas e Rodrigues (2001), ainda que esse efeito precise ser confirmado por estudos mais aprofundados.

A influência positiva do ácido indolbutírico na propagação vegetativa do gênero Cestrum foi relatada por Lopes et al. (2000), que observaram $100 \%$ de enraizamento em estacas de C. roseum submetidas a distintas concentrações do regulador vegetal. Fernandez et al. (2007) também detectaram maior índice de enraizamento (47\%) para estacas de $C$. nocturnum tratadas com AIB.

As estacas de $15 \mathrm{~cm}$ apresentaram número de folhas novas por estaca significativamente maior que as estacas de $8 \mathrm{~cm}$ (Tabela 5). Esse aspecto provavelmente se deve à presença de um maior número de gemas nas estacas longas, o que propicia maior brotação por estaca. Resultados similares foram encontrados para Fuchsia regia e Lippia alba, que apresentaram significativo aumento de brotação nas estacas de maior comprimento (BIASI; COSTA, 2003; ALCÂNTARA et al., 2008).

Tabela 5. Número de folhas novas por estaca de Cestrum corymbosum, considerando dois tamanhos de estacas submetidas a três diferentes concentrações de ácido indolbutírico (AIB), após 90 dias.

Table 5. Number of new leaves for cutting of Cestrum corymbosum, regarding two sizes of cuttings submitted to three different concentrations of indolebutyric acid (IBA), after 90 days.

\begin{tabular}{|c|c|c|c|c|}
\hline \multirow{2}{*}{$\begin{array}{l}\text { Tamanho das estacas } \\
(\mathrm{cm})\end{array}$} & \multicolumn{3}{|c|}{ AIB } & \multirow{2}{*}{ Médias } \\
\hline & $0 \mathrm{mg} . \mathrm{L}^{-1}$ & 1000 mg.L $L^{-1}$ & 2000 mg.L $L^{-1}$ & \\
\hline 8 & 12,1 & 12,6 & 10,5 & $11,7 \mathrm{~B}$ \\
\hline 15 & 14,7 & 17,7 & 13,1 & $15,2 \mathrm{~A}$ \\
\hline Médias & $13,4 \mathrm{a}$ & $15,1 \mathrm{a}$ & $11,8 \mathrm{a}$ & \\
\hline
\end{tabular}

Nota: médias seguidas da mesma letra maiúscula na vertical e minúscula na horizontal não diferem significativamente entre si pelo teste de Tukey ao nível de 5\%. Coeficiente de variação igual a 30,77\%.

\section{CONCLUSÕES}

- Sementes de Cestrum corymbosum, semeadas poucos dias após a coleta, apresentam germinação elevada, rápida e uniforme.

- C. corymbosum apresenta elevada taxa de sobrevivência e mediano crescimento em altura de suas plântulas após a repicagem.

- O período necessário para o pleno enraizamento de estacas de $C$. corymbosum é de 60 dias.

- Estacas de $8 \mathrm{~cm}$ são as mais adequadas para a propagação vegetativa dessa espécie, apresentando elevadas taxas de enraizamento e sobrevivência.

- O ácido indolbutírico nas concentrações de 1000 e $2000 \mathrm{mg} . \mathrm{L}^{-1}$ não favoreceu significativamente a sobrevivência, o enraizamento e o desenvolvimento de folhas em estacas de Cestrum corymbosum.

\section{AGRADECIMENTOS}

Os autores agradecem à Universidade Federal do Paraná, pelo apoio concedido no Laboratório de Análise de Sementes Florestais; à Sociedade Chauá, pela cessão da estrutura do Viveiro Chauá na implantação do experimento; e à engenheira florestal Anke Manuela Salzmann.

\section{REFERÊNCIAS}

ALCÂNTARA, G. B.; FERRONATO, M. L.; LIMA, D. M.; SANTOS, E. C.; SILVA, C. L.; RITTER, M.; BIASI, L. A. Enraizamento de estacas caulinares de brinco-de-princesa com diferentes comprimentos. Scientia Agraria, Curitiba, v. 9, n. 4, p. 575 - 578, 2008. 
AL-SAWAF, M. B.; SULTAN, S. M.; AL-ATRACKCHII, A. O. Propagation of some ornamental shrubs by hardwood cuttings. The Iraqi Journal of Agricultural Sciences, Hawler, v. 25, n. 1, p. 118 - 125, 1994.

ALTHAUS-OTTMANN, M. M.; LEAL, L.; ZUFFELLATO-RIBAS, K. C. Propagação vegetativa de manacá Brunfelsia uniflora (Pohl.) D. Don. Revista Brasileira de Horticultura Ornamental, Campinas, v. 12, p. $31-36,2006$.

BIASI, L. A.; COSTA, G. Propagação vegetativa de Lippia alba. Ciência Rural, Santa Maria, v. 33, n. 3, p. $455-459,2003$.

BRASIL. Ministério da Agricultura e Reforma Agrária. Regras para análise de sementes. Brasília: SNDA/DNDV/CLAV, 1992. 365 p.

CALDEIRA, M. V. W.; ROSA, G. N.; FENILLI, T. A. B.; HARBS, R. M. P. Composto orgânico na produção de mudas de aroeira-vermelha. Scientia Agraria, Curitiba, v. 9, n. 1, p. 27 - 33, 2008.

FERNANDEZ, S. L. R.; ÁlVAREZ, A. F.; LÓPEZ, M. M. G.; HERNÁNDEZ, N. P. B.; CASTILLO, C. A. M.; OROZCO, L. J. O.; SALERO, D. M.; JUÁREZ, D. R.; BECKLER, P. Z. Propagación asexual de huele de noche (Cestrum nocturnum L. var. mexicanus) en el Sur del D.F. In: CONGRESO NACIONAL DE LA SOCIEDAD MEXICANA DE CIENCIAS HORTÍCOLAS, 12., 2007, Zacatecas. Anais... Zacatecas: SOMECH, 2007. p. 228.

GARCIA, J.; JACOBSON, T. K. B.; FARIAS, J. G.; BOAVENTURA, R. F. Effectiveness of methods to increase the germination rate of jurubeba (Solanum paniculatum L.) seeds. Pesquisa Agropecuária Tropical, Goiânia, v. 38, n. 3, p. 223 - 226, 2008.

GONZAGA, A. P. D.; CARVAlHO, L. C. S.; ALMEIDA, H. S.; BRAGA, R. F.; ROCHA, E. A.; NUNES, Y. R. F. Germinação de sementes e estabelecimento de plântulas de Solanum lycocarpum St.Hill (Solanaceae) submetidas a escarificação mecânica, química e térmica. In: CONGRESSO DE ECOLOGIA DO BRASIL, 8., 2007, Caxambu. Anais... Caxambu: SEB, 2007. p. 1 - 2.

HARTMANN, H. T.; KESTER, D. E.; DAVIS JR., F. T.; GENEVE, R. L. Hartmann and Kester's plant propagation: principles and practices. 8. ed. New York: Prentice-Hall, Inc. Upper Saddle River, 2011. $880 \mathrm{p}$.

LAVIOLA, B. G.; LIMA, P. A.; WAGNER JÚNIOR, A.; MAURI, A. L.; VIANA, R. S.; LOPES, J. C. Efeitos de diferentes substratos na germinação e no desenvolvimento inicial de jiloeiro (Solanum gilo Raddi), cultivar verde claro. Ciência e Agrotecnologia, Lavras, v. 30, n. 3, p. 415 - 421, 2006.

LIMA, R. L. S.; SIQUEIRA, D. L.; WEBER, O. B.; CAZZETA, J. O. Comprimento de estacas e parte do ramo na formação de mudas de aceroleira. Revista Brasileira de Fruticultura, Jaboticabal, v. 28, n. 1, p. 3 - 86, 2006.

LOPES, J. C.; PEREIRA, M. D.; MARTINS FILHO, S. Germinação de sementes de cubiú em diferentes substratos e temperaturas. Revista Brasileira de Sementes, Londrina, v. 27, n. 2, p. 146 - 150, 2005.

LOPES, M. F.; JACOB, A. P.; BETTENCOURT, J. M. Estudos para a propagação vegetativa de algumas ornamentais de exterior. In: ENCONTRO NACIONAL DE PLANTAS ORNAMENTAIS, 3., 2000, Lisboa. Anais... Lisboa: Associação Portuguesa de Horticultura, 2000. p. 173 - 177.

LORENZI, H. Plantas daninhas do Brasil: terrestres, aquáticas, parasitas e tóxicas. 4. ed. Nova Odessa: Instituto Plantarum, 2008. 672 p.

LORENZI, H.; SOUZA, H. M. Plantas ornamentais no Brasil: arbustivas, herbáceas e trepadeiras. 4. ed. Nova Odessa: Instituto Plantarum, 2008. 1088 p.

MAGUIRE, J. D. Speed of germination aid in selection and evaluation for seedling emergence and vigor. Crop Science, Madison, v. 2, n. 2, p. 176 - 177, 1962. 
MIRANDA, Z. F. S.; MELLO, V. D. C.; SANTOS, D. S. B.; TILLMANN, M. A. A.; SANTOS, A. M.; SILVA, J. B. Avaliação da qualidade de sementes de berinjela (Solanum melongena L.). Revista Brasileira de Sementes, Londrina, v. 14, n. 2, p. 125 - 129, 1992.

OLIVEIRA, Y.; SILVA, A. L. L.; PINTO, F.; QUOIRIN, M.; BIASI, L. A. Comprimento das estacas no enraizamento de melaleuca. Scientia Agraria, Curitiba, v. 9, n. 3, p. 415 - 418, 2008.

PEREIRA, M. D.; SANTOS, C. E. M. dos; FILHO, S. M. Germinação de sementes de cubiú (Solanum sessiliflorum Dunal). Revista Brasileira de Ciências Agrárias, Recife, v. 6, n. 1, p. 79 - 84, 2011.

ROCHA, S. C.; QUEIROZ, J. A. L.; QUISEN, R. C.; ZUFFELLATO-RIBAS, K. C.; ALTHAUSOTTMANN, M. M. Enraizamento de estacas de manacá-de-cheiro (Brunfelsia uniflora (Pohl.) D. Don.) em diferentes concentrações de ácido indolbutírico em solução e em talco. Cultura Agronômica, Ilha Solteira, v. 13, p. 68 - 77, 2004.

SOARES, E. L. C.; VIGNOLI-SILVA, M.; MENTZ, L. A. O gênero Cestrum L. (Solanaceae) no Rio Grande do Sul, Brasil. Pesquisas: Botânica, São Leopoldo, n. 58, p. 263 - 282, 2007.

SOUZA, A. C.; VIERA, R. D.; CASTELLANE, P. D. Influência da exposição a baixas temperaturas na germinação e vigor de sementes botânicas de batata (Solanum tuberosum L.). Revista Brasileira de Sementes, Londrina, v. 19, n. 1, p. 18 - 21, 1997.

ZUFFELLATO-RIBAS, K. C.; RODRIGUES, J. D. Estaquia: uma abordagem dos principais aspectos fisiológicos. Curitiba: UFPR, 2001. 39 p. 